\title{
Segurança alimentar e mudanças no clima: o contexto internacional e o paradoxo brasileiro
}

Karina de Paula Carvalho

Rosa Livia Gonçalves Montenegro

\section{Resumo}

Este trabalho aborda os danos provocados pelo sistema alimentar global de base industrial à sociobiodiversidade e à sustentabilidade ambiental. O objetivo foi apontar o panorama global da problemática que leva a um conjunto de estratégias e ações com vistas a mitigar e reduzir possíveis danos. No passo dessa problematização, buscou-se questionar o conflito presente na agenda política brasileira para o setor agrícola. De um lado, há um amplo reconhecimento internacional das políticas transversais de proteção dos direitos sociais, em conjunto com a preocupação ambiental e climática. De outro, reconhece-se este setor como o maior consumidor de agroquímicos no mundo. Este contrassenso parece desafiar a segurança alimentar da população e a promoção de sistemas alimentares mais saudáveis. Para discutir essas questões realizou-se uma análise descritiva do sistema alimentar global e de seus danos à sociobiodiversidade. As considerações finais trazem os desafios e as alternativas para a sustentabilidade ambiental, econômica e social dos sistemas alimentares no Brasil e no mundo.

Palavras-chave | Brasil; mudanças climáticas; segurança alimentar e nutricional; sistemas alimentares; sustentabilidade.

Classificação JEL | Q18 Q54 Q56

Food security and climate change: the international context and the Brazilian paradox

\begin{abstract}
This work addresses the damage to socio-biodiversity and environmental sustainability that the industrial-based global food system causes. The objective was to point out the global panorama of the discussions about the effects of the problem, which leads to a set of strategies and actions, aimed at mitigating and reducing possible damages. Along with this problematization, it sought to question the conflict in the Brazilian political agenda in the agricultural sector. On the one hand, there is wide international recognition for the transversal policies on broad protection of social rights together with environmental and climate concerns. On the other hand, it is
\end{abstract}


recognized as the largest consumer of agrochemicals in the world. This nonsense seems to challenge the food security of the population and the promotion of healthier food systems. To discuss these issues, a descriptive analysis of the global food system and its damage to sociobiodiversity was carried out. The final considerations bring the challenges and alternatives that the literature points to the viability and environmental, economic and social sustainability of food systems in Brazil and in the world.

Keywords | Brazil; climate change; food and nutritional security; food systems; sustainability.

\section{JEL Classification | Q18 Q54 Q56}

\section{Seguridad alimentaria y cambio climático: el contexto internacional y la paradoja brasileña}

\section{Resumen}

Este trabajo aborda el daño que causa el sistema alimentario mundial de base industrial a la sociobiodiversidad y la sostenibilidad ambiental. El objetivo fue señalar el panorama global de las discusiones sobre los efectos del problema, lo que lleva a un conjunto de estrategias y acciones, encaminadas a mitigar y reducir los posibles daños. Junto a esta problematización, se buscó cuestionar el conflicto en la agenda política brasileña en el sector agrícola. Por un lado, existe un amplio reconocimiento internacional de las políticas transversales de protección de los derechos sociales junto con las preocupaciones ambientales y climáticas. Por otro lado, el sector es reconocido como el mayor consumidor de agroquímicos del mundo. Esta contradicción parece desafiar la seguridad alimentaria de la población y la promoción de sistemas alimentarios más saludables. Para discutir estos temas, se realizó un análisis descriptivo del sistema alimentario global y su daño a la sociobiodiversidad. Las consideraciones finales traen los desafíos y alternativas para la sostenibilidad ambiental, económica y social de los sistemas alimentarios en Brasil y en el mundo.

Palabras clave | Brasil; cambio climático; seguridad alimentaria y nutricional; sistemas alimentarios; sostenibilidad.

Clasificación JEL | Q18 Q54 Q56

\section{Introdução}

Em todo o mundo, os sistemas alimentares industriais estão sendo questionados em várias frentes, desde novas formas de cooperação e geração de conhecimento até o desenvolvimento de novas relações de mercado, que criam alternativas aos circuitos de distribuição convencionais (SHIVA, 2003; TRICHES; SCHNEIDER, 2015; WILLETT et. al., 2019; MALUF, 2021). O enfretamento dessas questões em termos teóricos e práticos trouxe à luz múltiplas conexões entre diferentes impactos, sejam eles: saúdes humana e dos ecossistemas, entre alimentação, pobreza e mudanças 
climáticas, e entre sustentabilidade social e ambiental. A perspectiva de colocar o alimento na centralidade dos problemas ambientais (WILLET'T et al., 2019; IPESFood, 2017) traz à tona esses dilemas que estão especificamente ligados à agricultura industrial - monoculturas intensivas no uso de insumos químicos, agrotóxicos e o uso preventivo de antibióticos, nos quais sistematicamente levam a resultados negativos e a vulnerabilidades.

As problematizações em torno dos conceitos de "sustentabilidade ambiental", "produção alimentar", "riscos sistêmicos", "mudança no clima" e "segurança alimentar e nutricional" são diversas. E surgem vários movimentos mundiais questionando e criando aportes e métodos de análise para fortalecer alternativas ao que se considera inseguro e insustentável. Os documentos das organizações internacionais, como EAT-Lancet (2019), IPES-Food (2017) e FAO-IPCC (2017) são analisados aqui para trazer o panorama global do problema alimentar, ambiental e climático. Além disso, as referências supracitadas serão centrais para a elaboração do presente estudo. No Brasil, essa questão avança sob conflitos inerentes da dinâmica dos sistemas alimentares e das agendas políticas. Como alternativa, está em construção pela literatura a noção de "sistemas alimentares descentralizados" (MALUF; LUZ, 2017). Essa perspectiva analisa a dinâmica dos sistemas alimentares que coexistem pela ação de diversos atores sociais, nos processos e tensões que conformam a política dos alimentos, com base numa abordagem multidimensional e multiescalar. A literatura abordada aponta a América Latina como referência para o estudo dos impactos dos sistemas alimentares e agrícolas. Há uma larga tradição no tratamento da problemática alimentar nessa região do continente americano (MALUF, 2006). O Brasil se insere nesse contexto com um amplo reconhecimento internacional pelas políticas transversais de ampla proteção dos direitos sociais, bem como dos efeitos de mudanças climáticas e da conservação da biodiversidade.

No entanto, o Brasil também é referência no uso de químicos na produção alimentar. Desde 2008, o país tornou-se o maior consumidor de agrotóxicos do mundo, quando, de acordo com o Dossiê da Abrasco (CARNEIRO, 2015), foram lançadas 673,9 mil toneladas desses produtos no meio ambiente. Nesse caso, os dados criam um paradoxo. De um lado está o compromisso de promover ações visando recompor cadeias e sistemas de produção agrícola e assegurar o acesso a alimentos voltadas para a revalorização da agricultura familiar e promoção da segurança alimentar por meio de mecanismos sustentáveis econômica, social e ambientalmente. E, por outro lado, averiguou-se que entre os anos de 2000 e 2007, a importação de agrotóxicos aumentou 207\%. O Brasil, sozinho, concentrava $84 \%$ das vendas de agrotóxicos da América Latina e 107 empresas com permissão para utilizar insumos banidos em diversos países (CONSEA, 2012). Desde 2016, a liberação para o uso de agrotóxicos em lavouras vem crescendo num ritmo bastante intenso: passou de 139 em 2015 para 439 em 2019 (PREITE SOBRINHO, 2019).

Esses dados revelam que o paradoxo verificado há uma década e meia no Brasil tem evoluído, não sem resistência, no sentido da hegemonia, no âmbito das políticas 
públicas, de uma concepção "modernizante" de modelo agrícola que aponta para o aprofundamento a insegurança alimentar, inclusive como decorrência das mudanças climáticas. Neste trabalho, discute-se o panorama mundial sobre o sistema alimentar de base industrial e como ele desafia a segurança alimentar e nutricional, bem como a biodiversidade. Especificamente, questiona-se acerca dos danos provocados por essa configuração do sistema alimentar pelo olhar da literatura nacional e internacional a partir de documentos que discorrem sobre o clima e seus possíveis impactos sobre os meios antrópico e biótico. Para tanto, será realizada uma análise descritiva do modelo de produção industrial e seus impactos sobre a biodiversidade, enfatizando seu lado paradoxal de produção em larga escala enquanto a fome no mundo cresce. O termo sistema alimentar será utilizado como sinônimo de sistema agroalimentar industrial ${ }^{1}$.

O trabalho está estruturado da seguinte forma: no primeiro item são apontados os efeitos ambientais negativos do sistema alimentar industrial em escala global, focando o comprometimento do sócio biodiversidade. Em seguida, será abordado o relatório do IPES-Food (2017), a respeito da mitigação climática na agricultura e as discussões em torno dessas questões. Na sequência, será discutido o relatório da EAT-Lancet (WILLETT et al., 2019), que propõe uma grande transformação alimentar pela perspectiva do Antropoceno. Depois, questiona-se as alternativas propostas no sentido de propor sistemas alimentares pela descentralização. A partir da análise desses documentos, e da literatura, questiona-se a problemática relativa ao paradoxo brasileiro no enfrentamento da questão alimentar e climática. Por fim, nas considerações finais discute-se possíveis encaminhamentos para a produção alimentar sustentável, em conjunto com a promoção da segurança alimentar e nutricional das populações.

\section{A dinâmica do sistema alimentar global}

A abordagem aqui utilizada propõe uma análise crítica a respeito dos problemas diversos que o sistema alimentar global vem causando à sociobiodiversidade global, com base em revisão bibliográfica sobre o tema. A tendência sistêmica desse sistema provoca diversos ciclos viciosos e coloca em risco a garantia da vida de muitas pessoas ao redor do mundo. Como discute Shiva (2003), o que chamou de "ameaça" aos sistemas de sustentação da vida em todo globo, sobretudo nos países pobres. Estes ciclos promovem riscos interligados e propulsores do aprofundamento da vulnerabilidade ecológica e social, por conta de "sistemas homogêneos". Este alerta

1 No Brasil, o sistema agroalimentar industrial pode ser interpretado como um processo dominante no sistema agroalimentar nacional e favorece a própria lógica de construção de políticas que sustentam o agronegócio (NIERDELE; WESZ JUNIOR, 2018). 
recai sobre o sistema alimentar global, caracterizado pelo monocultivo, com baixa ou nenhuma diversidade produtiva. Neste sentido, o tópico busca compreender os impactos à biodiversidade no contexto de sistemas alimentares e como estes vêm sendo abordados pela literatura nos cenários nacional e internacional.

A noção de "sistema alimentar" utilizada aqui tem como base as discussões de Maluf e Luz (2017, p. 216), os quais o entende como o modo que as pessoas se organizam no espaço e no tempo para acessar e consumir comida. Além dessa definição, os autores também abordam essa conceituação com base na ação direta e indireta dos atores sociais, como empresas, instituições financeiras e organizações públicas e privadas que formam o sistema nas "redes interdependentes ou encadeadas" em determinada área geográfica.

A abordagem que os autores propõem inserem questões diversas à problemática que envolve os sistemas alimentares. Essa noção discute a dinâmica sob uma perspectiva integrada, pela interação entre os níveis nacional e internacional, em todo o processo de produção, distribuição e consumo de alimentos. Por conta dessa dinâmica, os autores explicam que estão conformadas diversas questões, bem como consequências que abrangem múltiplas dimensões e de várias ordens. A discussão pretendida aqui aborda essa problemática para analisar como o sistema alimentar global provoca um dilema humano diante de um "conjunto de problemas globais que está danificando a biosfera e afetando a vida humana de maneira alarmante" (MALUF; REIS, 2013, p. 1). Decorre daí a questão de que os problemas são sistêmicos, sendo interligados e interdependentes, e, por assim dizer, não podem ser entendidos e resolvidos isoladamente.

De acordo com os autores, nos últimos 50 anos vêm ocorrendo efeitos negativos, como um círculo vicioso que, dentre muitos problemas, destaca-se a insegurança alimentar e nutricional. Estes, por sua vez, intensificaram "O desemprego, a precarização das relações de trabalho, sobretudo no que respeita às mulheres e negros e a piora nas condições de distribuição da renda e da riqueza, o que impactou negativamente as condições de acesso aos alimentos". Seus efeitos à saúde humana já se expressam por fenômenos "como as doenças cardiovasculares, a obesidade, o uso de drogas, como o álcool e o fumo” (MALUF; REIS, 2013, p. 8).

Diante dessas questões e problemas diversos este tópico busca então compreender os impactos à biodiversidade no contexto do sistema alimentar mundial. A critério de fazer uma contextualização internacional, os relatórios da The Lancet e do IPESFood são analisados para compreender o problema da questão alimentar mundial e das mudanças climáticas. A problemática alertada pelos relatórios são sentidas de maneira diferente em cada realidade, dada as diferenças entre países ao redor do globo. De acordo com o relatório Unravelling the food-health nexus: addressing practices, political economy, and power relations to build healthier food systems do IPES-Food (2017), os sistemas alimentares de hoje conseguiram fornecer comida abundante em muitas partes do mundo. Todavia, eles também representam algumas das maiores ameaças 
às saúdes humana, vegetal e ambiental e à prosperidade como um todo. Isto demonstra uma questão paradoxal e passível de muitas críticas.

Para Burlandy, Magalhães e Maluf (2006) isso só reforça a importância de enfatizar que os impactos são regidos por diversos fenômenos sistêmicos, além de inesperados. Quando associados, são altamente diversos em termos de onde eles se originam, quais tipos de condições requerem, a que estão associados e quem são os afetados. A respeito dessas questões, o relatório do IPES-Food (2017) indaga que a agricultura é a principal contribuinte para a poluição do ar em várias regiões no mundo. Essa questão raramente é abordada em relação à produção de alimentos ou em diálogo com os agentes alimentares e agrícolas. Por isso, o trabalho referenciado enfatiza a necessidade de explorar os nexos dos aspectos sociais, estruturais, determinantes ambientais e da saúde associados aos sistemas alimentares, e identificar intervenções que possam potencialmente beneficiar muitas pessoas ao mesmo tempo, garantir e melhorar as condições de vida da população.

Uma outra discussão levantada acerca dessa problemática diz respeito à dinâmica da produção de alimentos que ao longo dos anos, criou um processo de homogeneização das dietas alimentares, largamente baseadas na combinação de carboidratos e proteínas de origem animal, e os impactos ambientais generalizados (SCHNEIDER; SCHUBERT; ESCHER, 2016). Neste sentido, como discorrem Maluf e Luz (2017, p. 217), muitas questões ocorrem da conformidade dos diferentes sistemas alimentares coexistentes entre si. Os problemas diversos são resultados dos fluxos internacionais, marcados pelo protagonismo das "grandes corporações transnacionais e de alguns poucos e poderosos Estados nacionais ou blocos regionais". Por outro lado, com base nesses atributos, em meio a essa "interação entre diferentes sistemas alimentares", surgem diversos conflitos entre o sistema alimentar mundial e "os demais", como os que reúnem os pequenos agricultores. Esse último grupo de atores tem construído um aparato com base na "descentralização", e, cada vez mais, repercute ao pontuar a necessidade de criar processos inclusivos e modelos mais sustentáveis (MALUF; LUZ, 2017).

Neste sentido, em meio à hegemonia do sistema alimentar global pela produção de gêneros alimentares básicos, processados, vendido pela ideia de flexibilidade e facilidade de preparo, surge uma contra-hegemonia, formada por atores sociais que denunciam práticas insustentáveis e criam estratégias e ações como alternativas viáveis para a vida como um todo. Além da preservação de hábitos culturais e da diversidade, estes trazem como slogan a ideia de que especialização produtiva não rima com diversidade. Os autores deste processo de luta são os movimentos sociais, pela terra, agricultores familiares, ambientalistas, povos tradicionais, acadêmicos, dentre outros (REIS, 2018).

No que tange à saúde humana, aquelas pessoas mais vulneráveis, como a população pobre e os trabalhadores agrícolas, por exemplo, são as que sofrem maiores danos. Com base em Rocha (2020), os problemas diversos interligados ao modus operandi 
dos sistemas alimentares são marcados, frequentemente, pelo caráter de interdependência, que se auto reforçam, como ciclos viciosos. Esses ciclos jogam as populações mais propensas à insalubridade - como intoxicação aguda por pesticidas; exposição a doses baixas de substâncias químicas; às substâncias transmitidas pelo ar; a zoonoses e resistência antimicrobiana; condições de trabalho estressante (impactos sobre a saúde mental); poluição por nitratos e fósforo via escoamento de fertilizantes; doenças transmitidas por alimentos, dentre muitas outras que podem ser citadas. Além desse processo degradante, em termos ambientais e humanos, os danos causados pelo sistema alimentar global geram inúmeras condições cada vez mais desagradáveis que incidem, sobretudo, em localidades e territórios onde se encontram as pessoas com maior propensão à fome, às dietas pouco calóricas e nutritivas e em situação de insegurança alimentar (ROCHA, 2020). Assim, a forma como se produzem os alimentos e como se organizam os sistemas alimentares já apresenta vários emissários de sua insustentabilidade. A exemplo da suscetibilidade ao ataque de pragas e, evidentemente, no surgimento de doenças nocivas que acometem humanos, como a Covid-19 (CARVALHO, 2021).

Os conflitos inerentes ao sistema alimentar global marcam sua dinâmica e os rumos que a problemática originária desses entrelaçamentos promove no tempo e no espaço. Os problemas à sociobiodiversidade já são significativos, como aponta a literatura aqui analisada. Com base nisso, está em jogo a necessidade de criar estratégias e ações no presente para reverter ou mitigar seus efeitos para a garantia da vida e do meio ambiente. A questão alimentar é posta como uma forma de análise desses problemas, dado seu caráter de disputa entre os diferentes atores sociais, e abrange toda cadeia de produção, distribuição, consumo, e preparo dos alimentos.

\section{Mitigação climática e segurança alimentar e nutricional}

A análise dos impactos climáticos nos solos tem ignorado as ligações entre agricultura e a garantia da segurança alimentar e nutricional. Em parte, deve-se ao fato de os dados disponíveis serem muito díspares e de dimensões globais. Mas essa lacuna está sendo resolvida, por exemplo, graças ao desenvolvimento de dados globais sobre solos. Como a recente perspectiva que estabelece nexos entre diversas problemáticas, como os múltiplos motivadores da mudança no uso da terra e os efeitos mistos que este recai à produção alimentar. Em termos da preocupação com a segurança alimentar global, a descrição clara do impacto climático na terra como resultado de forças dirigidas pelos seres humanos é importante. Também pede ações para alcançar metas de mitigação, bem como objetivos de adaptação e resiliência (FAO-IPCC, 2017).

Segundo o IPES-Food (2017), o impacto indireto das mudanças no uso da terra é mediado pela perda de estoque de carbono, redução da água e ciclagem de nutrientes 
e, também, de habitat de muitas espécies de animais e plantas. Os impactos socioeconômicos indiretos incluem o aumento da insegurança alimentar e nutricional, menor renda e aumento da pobreza. Um estudo recente da FAO-IPCC (2017) estimou o custo anual das mudanças no uso da terra, em termos de perda de serviços ambientais do ecossistema, em torno de US\$230 bilhões por ano. Em terras secas, a perda líquida de produtividade das culturas tem sido registrada entre $10 \%$ e 30\% em muitas áreas, especialmente em partes da África, Austrália, Ásia Central e América Latina.

Em termos da produção alimentar, o impacto da mudança no uso da terra é misturado não apenas com oportunidades de sinergias, mas também trade-offs. Embora a expansão das terras cultiváveis possa aumentar a produção de alimentos a curto prazo, pode gerar um alto custo de biodiversidade e perda de ecossistema se as culturas substituírem biomas de alto valor (por exemplo, florestas tropicais ou manguezais). A avaliação global do solo, emitida em 2015 pelo Painel Técnico Intergovernamental sobre Solos (ITPS), como parte do primeira Assembleia Plenária da Parceria Global do Solo, lista vários processos que afetam a degradação do solo, incluindo a sua erosão, o declínio do carbono orgânico e o desequilíbrio de nutrientes. O estudo da FAO-IPCC, referenciado acima, documenta o importante papel da temperatura no estoque de carbono nas áreas boreais, concluindo que um grau de aquecimento adicional resultará em perda líquida significativa de carbono do solo na atmosfera.

Segundo esta pesquisa, já existem esforços para sustentar a intensificação da terra por meio de vários objetivos, incluindo a produção de alimentos e cumprimento das metas climáticas. Por exemplo, estão sendo realizadas experiências nos Estados Unidos para combinar técnicas e abordagens econômicas que integram o cultivo duplo, reduzem o período ocioso da terra, desenvolvem a mecanização e melhoram a degradação da terra. Outras técnicas de intervenção nos solos e ecossistemas em geral foram desenvolvidas, como traz o termo Green Infrastructure, utilizado em primeira acepção na década de 1990 para tratar da gestão do escoamento superficial, drenagem e prevenção de inundações (EEA, 2011). Benedict e McMahon (2006) posteriormente reformularam esta definição americana de Infraestrutura Verde, definindo-a como uma rede interconectada de áreas naturais e outros espaços que conservam os valores e funções dos ecossistemas naturais, sustentando a purificação do ar e água, providenciando uma série de benefícios para a população e protegendo a biodiversidade.

Da mesma forma, o Brasil havia se disposto a retardar o desmatamento na Amazônia por meio de uma série de incentivos que incluem melhorias tecnológicas, aplicação das regulamentações existentes e envolvimento das indústrias (como, por exemplo, soja e gado). No entanto, no caso brasileiro, o que se observou nos últimos anos é o aumento do desmatamento e de grilagem, além de queimadas intensas e devastadoras. O Instituto Nacional de Pesquisas Espaciais (INPE) divulgou em novembro de 2019 a estimativa da taxa de desmatamento para os nove estados da 
Amazônia Legal Brasileira. O valor estimado é de $9.762 \mathrm{~km}^{2}$ para o período de agosto de 2018 a julho de 2019. Esse valor representa um aumento de 29,54\% em relação à taxa de desmatamento apurada pelo Projeto de Monitoramento do Desmatamento na Amazônia Legal por Satélite - PRODES 2018, que foi de 7.536 $\mathrm{km}^{2}$ (INPE, 2019).

Este é um problema grave e, segundo a FAO (2006), o setor da agropecuária é de longe o que mais se utiliza de terras para fins antropogênicos. Pelo seu destaque na produção de alimentos, o Brasil figura no cenário mundial como um detentor do maior rebanho bovino comercial do planeta. A respeito disso, Rivero et al. (2009) apresentaram uma pesquisa sobre as possíveis causas do desmatamento na Amazônia. Os resultados evidenciaram que a pecuária bovina é a principal atividade de uso do solo na região e tem tomado proporções em todos os estados. Esta prática econômica se destaca com a primeira no ranking do impacto ambiental, seguida das queimadas, com as maiores emissões. O estudo mostrou que a pecuária bovina está fortemente associada ao desmatamento na região Amazônica e que o crescimento da agricultura em larga escala - muitas vezes visando produção de ração animal aumenta o efeito sobre o desmatamento ao produzir monoculturas para exportação e, por conseguinte, não garantir a segurança alimentar e nutricional das pessoas (RIVERO et al., 2009).

A respeito da emissão de Gases de Efeito Estufa (GEE), um estudo da FAO-IPCC (2017) evidencia que a participação da agricultura nessas emissões é grande, e, dado os aumentos esperados na produção de alimentos necessários até na década de 2050, será necessário um grande esforço para a mitigação no setor da agricultura. Segundo a pesquisa, as prioridades na redução de emissões de GEE devem se concentrar em opções que ofereçam sinergia para tornar os sistemas alimentares mais eficientes e contribuírem para o desenvolvimento econômico e a resiliência dos ecossistemas. Outro ponto que carece reforço é promover maiores esforços para lidar com as emissões ao longo da cadeia de valor alimentar, antes e no pós-colheita. Além disso, é necessário explorar as opções de mitigação associadas ao desperdício de alimentos, bem como no processo de transporte, armazenamento, processamento e embalagem de alimentos. Uma alternativa é promover o uso de fertilizantes biológicos de nitrogênio em todas as fazendas, de diversos tamanhos, ao redor do mundo, particularmente naquelas que cultivam leguminosas, pois levará à substituição parcial ou total do fertilizante mineral nitrogenado, uma importante fonte de emissão de óxido nitroso.

Estes estudos vêm mostrando que enquanto a preocupação for manter práticas de produção degradantes e que em nada atinge às demandas da crescente população mundial, cada vez mais será difícil reverter este processo e garantir a sustentabilidade da sociobiodiversidade terrestre. Nesse caso, para que os objetivos do desenvolvimento sustentável sejam alcançados, as ações antrópicas devem ser alteradas no sentido de preservar o que ainda temos e criar condições de produzir 
em respeito aos limites planetários, como preocupa o relatório da EAT-Lancet (2019).

Ao lidar com a mitigação climática na produção dos alimentos e a segurança alimentar e nutricional, é importante considerar o enorme consumo de água e a sua contaminação, outro impacto que a agropecuária provoca. Só a pecuária consome 8\% da água doce do volume total usado pela humanidade (FAO, 2006), considerando nessa conta a irrigação de lavouras destinadas à ração animal. As principais fontes de poluição ocorrem pela eutrofização, lançamento de hormônios, antibióticos, produtos químicos, dejetos animais, fertilizantes e pesticidas, além de sedimentos erodidos das pastagens e beiras de rios. Estes químicos contaminam o solo, a água e os alimentos para consumo humano. Além de comprometer a saúde das pessoas, dos animais e do ecossistema. A erosão é outro grande problema que a pecuária acarreta. Com a compactação de solos, reduz-se a absorção de águas para os lençóis freáticos, ressecando a terra e tornando-a menos produtiva, colaborando para queimadas e desertificação (NOVAES, 2008).

A conceitualização que ganhou destaque na área de gestão e controle ambiental é o emprego do termo “pegada hídrica”(PH) introduzido em 2002 por Arjen Hoekstra na reunião de peritos internacionais sobre o comércio de água virtual realizada em Delf, Holanda (SILVA et al., 2013). De acordo com os autores, o conceito de pegada hídrica tem sido usado como indicador do consumo de água de pessoas e produtos em diversas partes do mundo. No Brasil, esse tema é totalmente elementar, dada a política alimentar que se desenvolveu aqui. A pegada hídrica é definida como o volume de água total usada durante a produção e o consumo de bens e serviços, bem como o consumo direto e indireto no processo de produção. A maioria dos usos de água ocorre na produção agrícola, destacando também o significativo volume consumido e poluído nos setores industrial e doméstico.

No Brasil, a produção agrícola, com base na monocultura, apresenta-se como a mais nociva ao meio ambiente e à segurança alimentar e nutricional da população. Diante de todo cenário, a perspectiva da nutrição sobre os impactos climáticos na produção de alimentos ainda é limitada, pois até então não se teve em conta por completo a gravidade do que vem provocando à saúde humana, animal e dos ecossistemas. Esta perspectiva que entende esses processos de maneira sistêmica, discutido em Maluf e Reis (2013), e como trazem o IPES-Food, a EAT-Lancet, a FAO, é central para avaliar completamente o papel das mudanças no clima na segurança alimentar e nutricional. Os resultados do impacto são relatados principalmente em termos de desnutrição, tendo evidências recentes de uma diminuição na qualidade nutricional, ou seja, no conteúdo de proteínas e nutrientes das culturas cultivadas com CO2 elevado, surgimento de doenças e exposição a riscos.

Em resumo, a mudança climática também pode reduzir a diversidade genética e limitar a capacidade adaptativa. Existem relativamente mais informações locais, mas poucas avaliações globais ou regionais, embora análises qualitativas iniciais estejam 
disponíveis. Além disso, o aquecimento global deve alterar a composição nutricional dos alimentos. Também está em debate o alargamento da fome e de mortes evitáveis (má nutrição nos anos iniciais, doenças já erradicadas, como diarreias, desinterias, dentre outras que tem relação com o consumo de alimento e água). Neste sentido, o mundo está diante de uma urgente mudança nos modos de se relacionar com a natureza, pela sua ação antrópica, que vem carecendo de uma "grande transformação" (EAT-Lancet, 2019). Essa mudança nas culturas de produção e consumo alimentar é colocada como a ferramenta para se criar condições sustentáveis de vida na terra, sendo necessária para hoje.

\section{A saúde planetária no Antropoceno requer uma transformação}

O termo Antropoceno foi introduzido inicialmente nos debates científicos em 2000, quando o químico Paul Crutzen, ganhador do Prêmio Nobel de Química de 1995, utilizou-o no encontro do Programa Internacional Geosfera-Biosfera (IGBP) em Cuernavaca, México. Crutzen sugeriu que a humanidade estaria vivendo uma nova era, o Antropoceno. O termo já era utilizado, de forma não rigorosa, há algum tempo, mas só a partir daquele momento que ganhou maior destaque (OLIVEIRA, 2018).

De acordo com Issberner e Léna (2018), o termo foi criado para considerar o impacto da acelerada acumulação de gases de efeito estufa sobre o clima e a biodiversidade, e, da mesma forma, dos danos irreversíveis causados pelo consumo excessivo dos recursos naturais. Apesar dessa formulação, os autores acreditam que é preciso entendê-lo para a possibilidade de chamar de uma nova época geológica. Enquanto o debate continua entre cientistas, ainda precisam ser encontradas as soluções para os problemas imanentes. O fato é que o mundo já sofreu mudanças significativas e testemunha uma forma coletiva de negação ao que está posto. Essa visão, um tanto incoerente, vem deixando para o futuro incerto a responsabilidade de suas ações em prol de um ideal que há muito tempo vem sendo discutido como insustentável.

Como discorre Issberner e Léna (2018), nos últimos 10 anos os cientistas ambientais, como o sueco Johan Rockström, e o norte-americano Will Steffen e seus colegas do Centro de Resiliência de Estocolmo, estabeleceram uma lista de nove "limites" planetários que seriam perigosos de se atravessar. No entanto alguns deles já foram ultrapassados e já vêm mostrando seus riscos: mudança climática, cobertura vegetal, perda de biodiversidade e extinções e fluxos biogeoquímicos (com os ciclos do fósforo e do nitrogênio desempenhando um papel crucial). A passagem para uma nova era vem sendo delimitada pela taxa de extinção que se elevou no século XX, intensificada na primeira Revolução Industrial. Para Oliveira (2018), na história da Terra, já houve cinco grandes extinções, que marcaram 
mudanças de períodos. Agora estaria acontecendo a sexta grande extinção de espécies, com grande mudança no conteúdo fossilífero.

A questão posta é saber como enfrentar essas questões no Antropoceno. Para Oliveira (2018), a humanidade já conseguiu superar muitas delas e nunca esteve tão alimentada e rica como nessa nova época. No entanto, embora a vida tenha prosperado, ainda há 1 bilhão de pessoas em situação de fome no planeta. Considerando a estimativa de que em 2050 existirão 10 bilhões de pessoas no planeta, os questionamentos, na verdade, não giram em torno de enfrentar o Antropoceno, mas a pergunta a ser feita é: como administrar com mais sabedoria os recursos naturais para não construir uma autoaniquilação humana?

No que tange à produção alimentar, de acordo com a EAT-Lancet (2019), uma agenda integrada para a alimentação no Antropoceno ${ }^{2}$ reconhece que os alimentos formam um elo inextricável entre a saúde humana e a sustentabilidade ambiental. Assim, a produção global de alimentos deve operar dentro dos limites da saúde humana para garantir dietas saudáveis a partir de sistemas alimentares sustentáveis para quase 10 bilhões de pessoas até 2050 .

Segundo a EAT-Lancet (2019, p. 5), “a comida é a alavanca mais forte para otimizar a saúde humana e a sustentabilidade ambiental na Terra". Segundo este trabalho, a comida está a ponto de colocar o planeta em colapso porque o sistema alimentar hegemônico (o sistema alimentar agroindustrial) é insustentável. Há uma grande produção alimentar, mas ainda são recorrentes a fome e a desnutrição. Segundo o relatório, 820 milhões de pessoas ainda não têm comida suficiente em calorias e de qualidade nutritiva. $\mathrm{O}$ alarde é o de que a produção global de alimentos ameaça a estabilidade climática e a resiliência dos ecossistemas e já é considerado o maior degradador ambiental e da transgressão dos limites planetários. Dessa forma, alertam "[...] é urgentemente necessária uma transformação radical do sistema alimentar global. Sem ação, o mundo corre o risco de não cumprir os Objetivos de Desenvolvimento Sustentável (ODS) da ONU e o Acordo de Paris" (EAT-Lancet, 2019, p. 5). Posto isto, a Comissão concentra-se em dois "pontos finais" do sistema alimentar global. O primeiro diz respeito ao consumo final, com dietas saudáveis, e o segundo, à produção sustentável de alimentos. Esses fatores impactam desproporcionalmente a saúde humana e a sustentabilidade ambiental. Para além disso, afetando também a sociedade, a cultura, a economia e a saúde e bem-estar animal.

Com o objetivo de alcançar "a grande transformação alimentar" - uma série, sem precedentes, de ações tomadas por todos os sectores do sistema alimentar em todos os níveis que visam normalizar dietas saudáveis de sistemas alimentares sustentáveis - para dietas saudáveis até 2050, a Comissão lança uma agenda integrada de saúde

\footnotetext{
2 O Antropoceno, para a EAT-Lancet, é entendido como um novo período geológico, no qual a humanidade é a força dominante da mudança no planeta.
} 
e sustentabilidade, com duas metas científicas que definem um espaço operacional seguro para sistemas alimentares e permitem avaliar quais dietas e práticas de produção de alimentos juntas vão permitir a realização dos ODS e do Acordo de Paris (mantendo o aquecimento global abaixo de $2{ }^{\circ} \mathrm{C}$, almejando $1,5{ }^{\circ} \mathrm{C}$ e descarbonizará o sistema de energia global até 2050). "Isso inclui mais do que o dobro no consumo de alimentos saudáveis, como frutas, vegetais, legumes e nozes, e uma redução de mais de 50\% no consumo global de alimentares menos saudáveis, como açúcares adicionados e carne vermelha" (EAT-Lancet, 2019, p. 12). Todavia, isso se aplica, primariamente, em países mais ricos, pois entendem que algumas populações em todo o mundo dependem de meios de subsistência agropastoris e proteína animal do gado. Dadas estas considerações, o papel dos alimentos de origem animal nas dietas das pessoas deve ser cuidadosamente considerado em cada contexto e dentro das realidades locais e regionais.

O relatório lança algumas metas que devem ser cumpridas caso as nações queiram reduzir os danos causados pelo modelo insustentável de produção que mantém até o momento. São colocados um objetivo, duas metas e cinco estratégias. O objetivo é a transformação dos sistemas alimentares por meio de dietas saudáveis e sustentáveis. A primeira meta diz respeito às dietas saudáveis, que, segundo o relatório, consiste em um ótimo consumo calórico composto em grande parte de uma diversidade de alimentos à base de plantas, baixas quantidades de alimentos de origem animal, contêm gorduras não saturadas, e quantidades limitadas de grãos refinados, alimentos altamente processados e açúcares adicionados.

A segunda meta diz respeito à produção sustentável de alimentos. Os sistemas alimentares são entendidos como o elo entre o que é biótico, físico e antrópico, regulando o estado do planeta. Sabendo disso, a comissão propõe limites para que a produção global de alimentos permaneça amortizada, a fim de diminuir o risco de produção irreversível e mudanças potencialmente catastróficas no sistema terrestre. "Estes limites planetários para a produção de alimentos definem, de forma conceitual, o limite superior dos efeitos ambientais para a produção de alimentos numa escala global" (EAT-Lancet, 2019, p. 15). São apontadas cinco as estratégias para a "Grande Transformação Alimentar": (1) procurar obter um compromisso internacional e nacional para mudar para dietas saudáveis; (2) reorientar as prioridades agrícolas de produção de grandes quantidades de alimentos para produzir alimentos saudáveis; (3) intensificar de maneira sustentável a produção de alimentos para aumentar a produção de alta qualidade; (4) governança forte e coordenada da terra e dos oceanos; (5) reduzir pela metade as perdas e os desperdícios de alimentos, de acordo com os Objetivos de Desenvolvimento Sustentável da ONU.

Ao concluir, a comissão não deixa claro como essas estratégias se converterão em ações sólidas, nem classifica quem serão esses atores-chaves. Contudo, afirma que a adoção universal de uma dieta de saúde planetária ajudaria a evitar a degradação ambiental severa e evitaria aproximadamente 11 milhões de mortes humanas 
anualmente. Afirma, ainda, que a alimentação será uma questão definidora do século XXI, e que os dados são suficientes e fortes o bastante para justificar uma ação imediata. A questão que busca enfatizar é: como estratégias alternativas podem proteger a segurança alimentar? O que se tem pensado e desenvolvido sobre essas questões no Brasil?

No Brasil, a noção de "sistemas alimentares" envolve uma gama de questões e críticas. Isso porque advém do complexo processo que envolve as cadeias para seu abastecimento alimentar. Maluf e Luz (2017, p. 215), conforme abordado anteriormente, postulam que isso corrobora um maior apresso dado que o processo de abastecimento está além da disponibilidade física e da comercialização de bens, pois na medida em que as atividades se organizam, elas trazem em si determinantes que ditam os modos de se produzir, acessar ou consumir os bens. Dessa forma, a noção de "insegurança alimentar" aqui desenvolvida vem tratar não somente de carências nutricionais, apesar de já indicarem uma situação grave, mas também sobre como grupos sociais enfrentam problemas decorrentes da ingestão de alimentos não saudáveis, pobres em nutrientes, ocasionando riscos à saúde, tais como sobrepeso, obesidade e hipertensão. Assim, os dados mostram que a insegurança alimentar de determinada comunidade reflete os efeitos da tendência do "sistema alimentar dominante" que promove a homogeneização dos processos produtivos e de consumo.

Nestes termos, o abastecimento alimentar se constitui como "um sistema interrelacionado e interdependente" e nele está presente "um conjunto heterogêneo de agentes privados e organizações públicas”, mantendo relações rigorosas entre mercados locais, regionais, nacionais e internacionais (MALUF; LUZ, 2017, p. 216). É nos termos da definição de "sistemas alimentares", entendidos como "redes interdependentes de atores" em determinada localidade, que a noção de "sistemas alimentares descentralizados" se assenta. Com base na referência acima, a noção de "sistemas alimentares descentralizados" (SAD) - que está em construção pela literatura nacional - é entendida nos formatos dos sistemas como redes de atores, na ideia de interdependência ou encadeamento e a correlação com uma área geográfica determinada. É nestas áreas que os diferentes sistemas coexistem na alimentação das pessoas, famílias e comunidades pelas manifestações de práticas tradicionais e modernas.

Esta perspectiva discute que em meio às dinâmicas dos circuitos e fluxos dos sistemas alimentares estão também escoamentos de menor escala e amplitude espacial. Dessa forma, pressupõe que estes são mais suscetíveis à circulação de alimentos menos processados e mais diversos em termos socioambiental e cultural dos países. A noção de SAD então se formula pela existência de "sistemas alimentares" entrelaçados entre si. Isto ocorre porque os atores locais se apropriam das características gerais do sistema alimentar e, nas dinâmicas locais, eles o delineiam e lhe atribuem características próprias, considerando cada contexto socioespacial. 
A ideia de "sistema alimentar", como o nome já sugere, remete à noção sistêmica que requer a presença de dois elementos-base, que são os "fluxos de interdependência" e os "mecanismos de coordenação" entre seus componentes. $\mathrm{Na}$ visão dos autores, essa caracterização parece ser suficiente para a abordagem de sistemas alimentares e a noção de SAD se destaca como um tipo de arranjo entre vários deles. Essa perspectiva também contribui para identificar interdependências para além "dos limites das relações técnico-produtivas entre agentes econômicos para incorporar o financeiro, o simbólico (determinante do consumo) e outros fatores" (MALUF; LUZ, 2017, p. 218). Segundo os autores, muitos destes fatores são definidos no plano nacional, e se conformam nestes termos, no "sistema alimentar nacional" no que tange às políticas públicas e aos temas que envolvem relações desiguais.

\section{O enfrentamento da questão alimentar e climática no Brasil}

Esse tópico apresenta o reconhecimento internacional que o Brasil conquistou dada a elaboração de uma política alimentar pela noção de "segurança alimentar e nutricional". No conjunto da condução da política alimentar e agrária, ocorreram conflitos de agenda política que impediram (e ainda impedem) a solução de problemas diversos. A problemática se intensifica quando ocorre o desmonte dessa política alimentar por parte da ascensão de governos ultraliberais, consoante com agravamento da questão ambiental. Essas questões muito contribuíram para a ampliação dos problemas alimentares, ambientais e climáticas. Deste modo, surgem os desafios para política alimentar e a segurança alimentar e nutricional no país.

Nas últimas décadas, o Brasil buscou soluções originais para a eliminação da fome e da pobreza, e obteve resultados promissores. Para a FAO (2016), o Brasil é destaque pelo enfoque de Doble $\mathrm{Via}^{3}$. A atuação dos governos juntamente com a sociedade civil foi importante para enfrentar os dilemas contemporâneos. Como a dinâmica socioeconômica, em especial nos temas da pobreza, da fome, dos efeitos das mudanças climáticas, da conservação da biodiversidade e do comércio justo e inclusivo.

No Brasil, a elaboração de um conceito de Segurança Alimentar e Nutricional (SAN), atrelado ao Direito Humano à Alimentação Adequada e Sustentável nas duas últimas décadas evidenciou um processo fértil que sempre esteve aliada à luta pela democracia e pela justiça social e econômica. A construção da Segurança Alimentar e Nutricional no Brasil tem mobilizado, há mais de duas décadas,

\footnotetext{
${ }^{3} \mathrm{O}$ enfoque Doble Via combina e integra a urgente e necessária assistência às famílias mais vulneráveis, em situação de emergência, com processos mais longos e medidas estruturantes, que permitem o acesso aos direitos fundamentais consagrados em compromissos assumidos pelos países da região em diversos fóruns internacionais e globais (FAO, 2016). Disponível em: http://www.fao.org/3/a-i5335o.pdf.
} 
organizações e movimentos sociais, governos e pesquisadores, entre outros atores sociais. Segundo Leão e Maluf (2012), a adoção de um sistema nacional para a oferta das políticas públicas também veio atender a tendência nacional de compreender os diversos setores da sociedade de maneira interdependente e indivisível. Então, a SAN se materializou na Lei N. 11.346, em 15 de setembro de 2006, e instituiu o Sistema Nacional de Segurança Alimentar e Nutricional (Sisan) com as condições em que se produz e se comercializa o alimento, sem comprometer necessidades essenciais tendo como base práticas alimentares promotoras de saúde, que respeitem a diversidade cultural e que sejam social, econômica e ambientalmente sustentáveis.

A noção de segurança alimentar utilizada nos dias de hoje tem suas raízes na associação entre a disponibilidade e acessibilidade de alimentos e a segurança das populações e dos Estados, o que a converte num objetivo de políticas públicas. Este projeto nacional, pautado na construção de espaços de participação, foi o elo que possibilitou a construção de uma agenda democrática para o desenvolvimento sustentável. O projeto social brasileiro pautado em promover o desenvolvimento, seja em sua acepção social, sustentável, econômico obteve resultados consideráveis em termos da redução da pobreza, da desigualdade social dentre outros componentes que compõem a qualidade de vida. No entanto, muitos desses direitos e políticas públicas regrediram nos últimos anos, pelos novos rumos tomados pelos governos com propostas ultraliberais e menos progressistas. Segundo Salles Costa (2021), do Instituto de Nutrição Josué de Castro, em cinco anos, o brasileiro regrediu 15 anos (2018-2003), pela perda de direitos conquistados neste período. Mesmo nos governos progressistas já se presenciava um paradoxo na condução da política alimentar e ambiental, marcado pela contradição de agendas políticas.

Com os governos liberais esse paradoxo continua ativo e conflitante. Isto porque a política alimentar e ambiental evidentemente está inclinada à agroindústria. No cenário internacional, aumenta o olhar para o Brasil, por parte dos países da Cúpula do Clima sobre a condução das medidas de mitigação dos danos ambientais e mudanças climáticas. De acordo com o Instituto Nacional de Pesquisas Espaciais (Inpe), referenciado acima, em junho de 2020 a destruição da floresta amazônica cresceu cerca de 10\% em relação ao mesmo mês de 2019 , ainda que nesse ano o registro de área derrubada foi considerado como a maior em uma década.

A condução da política ambiental e alimentar brasileira tem alertado o mundo pelo crescimento constante do desmatamento e tem aumentado a desconfiança internacional em relação à gestão ambiental no governo Bolsonaro. Essa problemática continua sendo uma questão paradoxal. De acordo com o Research Program on Climate Change, Agriculture and Food Segurity (CCAFS, 2019), a América Latina é uma das regiões do planeta mais vulneráveis às mudanças no clima. Isso se dá devido suas características socioeconômicas, geográficas e institucionais. Particularmente, o setor agrícola apresenta alta sensibilidade às variações climáticas, e a região enfrenta importantes perdas potenciais em biodiversidade e vidas 
humanas devido aos eventos climáticos extremos. A preocupação ocorre devido suas características históricas já conhecidas no mundo todo: indicadores alarmantes de fome, miséria extrema e desigualdades sociais latentes. Tudo isso ligado a crimes ambientais e riscos da mudança no clima que surte efeitos na população mais pobre. O Brasil é um país de grande importância nessa região, destacando sua sucedida agenda política de redução da miséria e da fome, juntamente com a questão ambiental, em um conjunto de políticas públicas implementadas transversalmente, como abordado acima.

Por outro lado, o Brasil além de ser reconhecido internacionalmente pelo compromisso com a promoção da segurança alimentar e nutricional, o país é o maior consumidor de agroquímicos no mundo (CARNEIRO, 2015). A respeito disso, o Conselho Nacional de Segurança Alimentar e Nutricional (CONSEA, 2012) - extinto pelo governo Bolsonaro em 2019 - alerta que no Brasil o uso de agrotóxicos é uma violação do direito humano à alimentação adequada. De acordo com o Consea (2012), o fato de o Brasil ser o maior mercado de agrotóxicos do mundo, em parte, é derivado da adoção de um modelo de desenvolvimento que se baseia nos princípios da chamada "Revolução Verde". Esse modelo, ao tornar-se preponderante, instituiu o que é hoje chamado de "agricultura convencional" e se sustenta na produção em grande escala, monocultora, branda em mão de obra e intensiva em insumos, como máquinas, equipamentos de irrigação, entre os quais se destacam agrotóxicos, sementes transgênicas e rações.

Outra característica desse tipo de agricultura é o fato de estar voltada predominantemente para a exportação. A transgenia á apenas a versão mais recente desse processo, iniciado nos anos 1970. Inicialmente, um dos argumentos dos defensores da proliferação dos transgênicos era que seu uso reduziria o uso de agrotóxicos. Contudo, assiste-se hoje a uma realidade totalmente oposta - no médio prazo, esses cultivos tendem a demandar muito mais insumos químicos. $\mathrm{O}$ alarme do CONSEA está no seguinte fato: o segmento usualmente denominado agronegócio é o principal consumidor de agrotóxicos no país (são responsáveis por quase $90 \%$ da demanda e possuem $75 \%$ das áreas de plantio). Ao mesmo tempo, ainda que consuma relativamente menos desses produtos, uma parcela significativa da agricultura familiar faz uso de agrotóxicos, o que se deu em função da difusão do uso de técnicas dependentes de veneno.

Existem termos legais de controle sobre o uso de agrotóxicos no Brasil. A Lei de Agrotóxicos e afins N. 7.802, de julho de 1989, estabelece que os agrotóxicos podem somente ser utilizados no país se forem registrados em órgão federal competente, de acordo com as diretrizes e exigências dos órgãos responsáveis pelos setores da saúde, do meio ambiente e da agricultura. Dessa forma, a responsabilidade fica para

\footnotetext{
${ }^{4}$ Por meio da Medida Provisória N. 870 (MP 870), editada pelo presidente Jair Bolsonaro em seu primeiro dia de governo, o Consea foi extinto, o que fragiliza sobremaneira o funcionamento do Sisan e compromete processos de garantia do Direito Humano à Alimentação Adequada em todas as esferas de governo.
} 
os três ministérios: Ministério da Saúde (MS), Ministério da Agricultura, Pecuária e Abastecimento (Mapa) e Ministério do Meio Ambiente (MMA), por meio do Instituto Brasileiro do Meio Ambiente e dos Recursos Naturais Renováveis (Ibama). De acordo com o art. $2^{\circ}$, os três ministérios podem desaconselhar a utilização dos produtos registrados quando o país for alertado nesse sentido, por organizações internacionais responsáveis pela saúde, alimentação ou meio ambiente, das quais o Brasil é membro integrante ou signatário de acordos. No entanto, apesar do alarme de diversas instituições nacionais e internacionais sobre os riscos dos agrotóxicos em todo o mundo, os dados registram aumentos históricos na liberalização de agroquímicos no ano de 2019. De acordo com o Moraes (2019), no início de 2019 existiam no Brasil cerca de 13.300 registros de agrotóxicos. Em termos de ingredientes ativos, em 2017, havia 517 cujo uso era autorizado no Brasil e 97 que haviam sido banidos.

Segundo Dossiê publicado em 2015 pela Associação Brasileira de Saúde Coletiva (Abrasco) (CARNEIRO, 2015) e realizado em conjunto com o Ministério da Saúde: 64\% dos alimentos no Brasil são contaminados por agrotóxicos; 34.147 intoxicações por esses produtos foram notificadas no Sistema Único de Saúde entre 2007 e 2014; 288\% foi o percentual de aumento do uso dos agrotóxicos no Brasil entre 2000 e 2012 e o faturamento da indústria de agrotóxicos no Brasil em 2014 foi de 12 bilhões de dólares. Essa realidade coloca o Brasil, desde 2008, na posição de maior mercado mundial de agrotóxicos. O dossiê alerta que o comportamento dos agrotóxicos na natureza é complexo, já que a seu uso pode contaminar a água e o solo e seus componentes podem ser levados por meio da chuva e dos ventos, dificultando a avaliação dos seus efeitos. Além disso, ao longo do percurso, o agrotóxico sofre processos químicos, biológicos e físicos que podem alterar o seu comportamento. Compreende-se que se as propriedades desses produtos podem ser alteradas, as consequências e riscos desses novos subprodutos serão desconhecidas. O documento ainda denuncia que a forma de produção de alimentos com base em agroquímicos está envenenando o solo, a biodiversidade, os agricultores e os consumidores. Os agricultores que trabalham com a aplicação desses produtos e a população que vive próximo às plantações são as mais vulneráveis, pois estão em contato direto com os produtos. Mas esse risco não se restringe a eles: toda a população brasileira está exposta à contaminação quando consome esses alimentos.

Segundo dados da Organização Mundial da Saúde (OMS), compilados no Dossiê da Abrasco (CARNEIRO, 2015), as principais doenças relacionadas à intoxicação por agrotóxicos são: arritmias cardíacas, lesões renais, câncer, alergias respiratórias, doença de Parkinson, fibrose pulmonar, entre outras. Um exemplo de contaminação foi retratado em um estudo da Universidade Federal do Mato Grosso (UFMT) que verificou a contaminação por agrotóxicos no leite materno de mães que moravam em áreas urbanas. O dossiê mostrou ainda que, por meio do Programa de Análise de Agrotóxicos em Alimentos (PARA), a Agência Nacional de 
Vigilância Sanitária (Anvisa) identificou os produtos que apresentavam os maiores níveis de contaminação em 2009. São eles: pimentão, morango, uva, cenoura, alface, tomate, mamão e laranja. A Anvisa também mostrou que um terço dos alimentos consumidos diariamente pelos brasileiros estão contaminados e, dentre eles, $28 \%$ apresentam componentes não autorizados ou em quantidade que excede o limite autorizado.

Segundo Carneiro (2015), no caso do Brasil, a contaminação da água por agrotóxicos pode ser 5 mil vezes maior do que o máximo permitido na Europa. A gravidade do problema chega a um nível em que a utilização de agrotóxicos gera cada vez mais dependência, pois como não são respeitados os processos naturais da produção de alimentos, a utilização desses produtos químicos vai diminuindo a fertilidade do solo. Como consequência, o solo pobre em nutrientes e aumenta a necessidade de agrotóxicos e adubos químicos. Além disso, quando a semente é geneticamente modificada, os agricultores ficam dependentes da própria semente e de defensivos específicos. A saída viria pela substituição desses produtos por outros menos perigosos ou por técnicas integradas de manejo, que diminuiriam a dependência dos químicos. A produção agroecológica pode ser uma alternativa promissora e para isso seria necessário um período de transição da produção convencional para esse outro modelo.

A discussão que está em curso sobre os "sistemas alimentares descentralizados" mostra um esforço de muitos brasileiros, presentes em vários movimentos, como discutido anteriormente, que caminham no sentido de propor novas práticas de manejo das culturas alimentares. A descentralização dos sistemas, com a produção alimentar local voltada às suas características, em respeito às culturas alimentares, permite reestabelecer novas relações nos sistemas alimentares e promover dinâmicas considerando cada contexto socioespacial. Os ganhos ambientais e sociais podem ser diversos, desde a relações mais sustentáveis com a natureza, a circuitos curtos de cadeias alimentares mais próximas dos consumidores e com a disponibilidade de alimentos mais ricos em nutrientes.

Mas a possível "transformação" para sistemas alimentares mais saudáveis passa pelos ordenamentos políticos e o compromisso de todos os envolvidos, partindo do Estado, em criar estratégias contínuas e meios para garantir que o trabalho não seja descontinuado. Como visto, o enfrentamento da questão ambiental e climática esbara em conflitos diversos e exige o reconhecimento do alimento e da alimentação na complexidade dos sistemas alimentares. Isso implica em reconhecer que o alimento e a alimentação devem ser tidos "como elemento nucleador da observação que joga luz sobre os atores, processos e tensões que conformam a política dos alimentos, com base numa abordagem multidimensional e multiescalar" (MALUF, 2021, p. 8). 


\section{Considerações finais}

A partir das problematizações em torno dos desafios imbricados nas estratégias para se promover sustentabilidade ambiental, a produção alimentar e a segurança alimentar e nutricional estão o conhecimento dos impactos dos riscos sistêmicos e das mudanças climáticas. Nesse sentido, observa-se que algumas medidas podem ser propostas, a exemplo de um novo modelo de produção. Essa visão encontra guarida em trabalhos nacionais e internacionais que alertam para a gravidade da problemática gerada pelos sistemas alimentares. Vimos também que os sistemas alimentares vêm sendo estudados de maneira multidimensional e multiescalar para abordar a realidade sistêmica e os ciclos viciosos que colocam em risco milhões de pessoas ao redor do globo. Essa abordagem que está em construção, permite compreender melhor essas questões e propor alternativas para práticas degradantes e insustentáveis.

Os documentos internacionais, por exemplo, colocam que um dos modelos de produção adotados como alternativa hoje é a agroecologia, que tem como propósito desenvolver um estilo de agricultura mais sustentável, com uma perspectiva sistêmica da natureza. Além de ser ambientalmente mais sustentável, a agroecologia é socialmente mais justa, pois permite que pequenos agricultores produzam alimentos com um método menos caro que o industrial. Esses documentos internacionais aqui discutidos, recomendam aos governos que sejam elaboradas políticas públicas com vistas a incentivar e permitir que a produção agroecológica possa, de fato, ser uma alternativa. No entanto, como vimos para a realidade brasileira, os conflitos de agendas políticas impedem que esse modelo se concretize.

No caso brasileiro, a experiência na construção de um Sistema Nacional de Segurança Alimentar e Nutricional (Sisan), colocou-lhe em um lugar estimado internacionalmente ao trazer em seu conjunto princípios os aspectos de sustentabilidade ambiental, direitos sociais e produção alimentar segura e justa. A mudança de propostas políticas e sociais, bem como os diversos conflitos inerentes à condução de medidas para mitigar os danos da agricultura industrial, têm causado divergências internacionais e colocado o Brasil no centro da preocupação da questão climática.

Assim, o enfrentamento da questão ambiental e climática é inerente ao modelo de agricultura adotado e os rumos que os sistemas alimentares delineiam nos processos e tensões da política alimentar. Uma possível saída para a sustentabilidade viria de um sistema alimentar sob a perspectiva da descentralização, na dinâmica econômica, e sua contribuição social em modelos de desenvolvimento que tenham a preocupação com a segurança alimentar e nutricional (como no caso brasileiro) como componente estratégico, sobretudo, quando se atenta para a problemática maior do impacto dos sistemas alimentares sobre os países emergentes ou em desenvolvimento. Em países como o Brasil, a agricultura possui significativa 
importância na geração de emprego e renda no conjunto das atividades para o abastecimento dos mercados.

A superação das características do atual sistema alimentar supõe que sua dinâmica afeta as condições de acesso aos alimentos e está relacionado à biodiversidade; acesso ao alimento adequado e nutritivo; a precarização das relações de trabalho, aos insumos mecânicos e químicos. Pela perspectiva descentralizada coloca que as funções dos sistemas alimentares é a produção de alimentos e outros bens agrícolas com base na promoção de equidade social; compreender os aspectos de diversidade cultural; sustentabilidade; a reprodução socioeconômica das famílias rurais; promoção da segurança alimentar das próprias famílias rurais e da sociedade e a preservação dos recursos naturais e da paisagem rural. Sendo assim, um dos maiores desafios da promoção da segurança alimentar está imbricado nos aspectos que compõe a organização da produção alimentar mundial de base industrial. O Brasil, apesar do seu histórico estimado de estratégias e ações transversais respeitadas em todo o mundo, segue pela contramão, ao incentivar práticas agroindustriais criticadas e abolidas em grande parte do mundo.

Este trabalho veio contribuir para estas discussões ao apontar que estes dilemas contemporâneos estão mais do que nunca ligados e se reproduzem. Dessa forma, não há como abordá-las por outra perspectiva que não seja multidimensional, multiescalar e transversal. O esforço feito aqui em trazer essa abordagem contribui para a problemática abordada e para que outros trabalhos possam ser feitos e conduzidos no sentido de propor novas formas compreender questões de maneira interligada.

\section{Referências}

BENEDICT, M. A.; MCMAHON, E. T. Green infrastructure: linking landscapes and communities. Washington: Island Press, 2006.

BURLANDY, L.; MAGALHÃES, R.; MALUF, R. Construção e promoção de sistemas locais de segurança alimentar e nutricional: aspectos produtivos, de consumo, nutricional e de políticas públicas (= Relatórios Técnicos, 3). Rio de Janeiro: CPDA/UFRRJ, 2006. Disponível em: http://www.ufrri.br/cpda/ceresan/docs/relatoriotecnico3.pdf. Acesso em: 15 nov. 2019.

CARNEIRO, F. F. Dossiê ABRASCO: um alerta sobre os impactos dos agrotóxicos na saúde. Rio de Janeiro: EPSJV; São Paulo: Expressão Popular, 2015. 
CARVALHO, K. P. As conexões entre o sistema alimentar dominante e a covid19: desafios à segurança alimentar e nutricional no tempo presente e após.

Segurança alimentar e nutricional, Campinas, vol. 28, p. e021011, 2021. DOI: 10.20396/san.v28i00.8661416. Disponível em:

https://periodicos.sbu.unicamp.br/ojs/index.php/san/article/view/8661416. Acesso em: 3 jun. 2021.

CCAFS-Climate Change Agriculture and Food Security. Climate change adaptation and mitigation. Research Program on Climate Change Agriculture and Food Security, 2019. Disponível em: https://cgiar.org/research/programplatform/climate-change-agriculture-and-food-security/. Acesso em: 20 dez. 2019.

\section{CONSEA. Os impactos dos agrotóxicos na segurança alimentar e} nutricional: contribuições do Consea. Brasília/DF: -Conselho Nacional de Segurança Alimentar e Nutricional, 2012. Disponível em: http://www.contraosagrotoxicos.org/index.php/materiais/relatorios/osimpactos-dos-agrotoxicos-naseguranca-alimentar-e-nutricional-contribuicoes-doconsea/download. Acesso em: 20 dez. 2019.

EAT-Lancet Commission. Dietas Saudáveis A Partir De Sistemas Alimentares Sustentáveis: Alimento, planeta e saúde. Relatório Sumário. This report was prepared by EAT and is an adapted summary of the Commission Food in The Anthropocene: the EAT-Lancet Commission on Healthy Diets From Sustainable Food Systems. 2019. Disponível em: https://eatforum.org/content/uploads/2019/04/EATLancet_Commission_Summ ary_Report_Portugese.pdf. Acesso: 20 set. de 2020.

EEA [Green Infrastructure and Territorial Cohesion]. The concept of green infrastructure and its integration into policies using monitoring systems (= EEA Technical Report, 18). Copenhagen: European Environment Agency, 2011.

FAO (Organização das Nações Unidas para a Agricultura e a Alimentação). Superação da fome e a pobreza rural: iniciativas brasileiras. Coordenação: Alan Jorge Bojanic. Capítulo 1 e 2. Brasília, 2016.

FAO - Food and Agriculture Organization of the United Nations. Livestock's long shadow. Rome: 2006. 
FAO. Grupo de Trabalho intergovernamental para a elaboração de um conjunto de diretrizes voluntárias com o objetivo de apoiar a realização progressiva do direito a uma alimentação adequada no contexto da segurança alimentar nacional. Diretrizes voluntárias para o direito à alimentação. Roma: Food and Agriculture Organization of the United Nations, set. 2004.

FAO-IPCC. Expert meeting on climate change, land use and food security meeting report. Roma: Food and Agriculture Organization of the United Nations, jan. 2017.

\section{INPE. A estimativa da taxa de desmatamento por corte raso para a} Amazônia Legal em 2019 é de 9.762 km². Brasília: Instituto Nacional de Pesquisas Espaciais/Ministério da Ciência, Tecnologia, Inovações e Comunicações, 2019. Disponível em: http://www.inpe.br/noticias/noticia.php?Cod_Noticia=5294. Acesso em: 20 jan. 2020.

IPES-Food. Unravelling the food-health nexus: addressing practices, political economy, and power relations to build healthier food systems, 2017. Disponível em: http://www.ipes-food.org/_img/upload/files/Health_FullReport(1).pdf. Acesso em: 20 set. 2018.

ISSBERNER, L. R.; LÉNA, P. Antropoceno: os desafios essenciais de um debate científico. O Correio da UNESCO, n. 2, 2018. Disponível em: https://unesdoc.unesco.org/ark:/48223/pf0000261901_por?posInSet=1\&queryI d=09c8f5a5-c247-46d5-874c-1befaabcca84. Acesso em: 15 mai. 2020.

LEÃO, M.; MALUF, R. S. A construção social de um sistema público de segurança alimentar e nutricional: a experiência brasileira. Brasília: ABRANDH, 2012.

MALUF, R. S. Decentralized food systems and eating in localities: a multi-scale approach. Revista de Economia e Sociologia Rural, 59 (4), e238782. 2021. https://doi.org/10.1590/1806-9479.2021.238782.

MALUF, R. S. Segurança alimentar e fome no Brasil: 10 anos da Cúpula Mundial de Alimentação (= Relatórios Técnicos, 2). Rio de Janeiro: CERESAN, ago. 2006. 
MALUF, R. S.; LUZ, L. F. "Sistemas alimentares descentralizados: um enfoque de abastecimento na perspectiva da soberania e segurança alimentar e nutricional". In: MALUF, Renato S.; FLEXOR, Georges (Org.) Questões agrárias e agrícolas e rurais: conjunturas e políticas públicas. Rio de Janeiro: E-papers, 2017.

MALUF, R. S.; REIS; M. C. "Segurança alimentar e nutricional na perspectiva sistêmica”. In: ROCHA, C.; BURLANDY, L.; MAGALHÃES, R. (Org.)

Segurança alimentar e nutricional: perspectivas, aprendizados e desafios para as políticas públicas. Rio de Janeiro: Ed. FIOCRUZ, 2013.

MORAES, Rodrigo F. (Org.) Agrotóxicos no Brasil: padrões de uso, política da regulação e prevenção da captura regulatória. Brasília: IPEA, set. 2019.

NIERDELE, P. A.; WESZ JUNIOR, V. As novas ordens alimentares. Porto Alegre: Ed. UFRGS, 2018. 432p.

NOVAES, W. Meio ambiente no século 21. Org. André Trigueiro. Campinas: Armazém do Ipê, 2008.

OLIVEIRA, Sonia Maria Barros de. Os critérios para a definição da nova época geológica, o Antropoceno. Instituto de Estudos Avançados (IEA) da Universidade de São Paulo. São Paulo, maio 2018. Disponível em http://www.iea.usp.br/noticias/conversa-sobre-o-antropoceno. Acesso em 2020.

PREITE SOBRINHO, W. Número de agrotóxicos liberados no Brasil é o maior dos últimos dez anos. 2019. Disponível em: https:// noticias.uol.com.br/meio-ambiente/ultimasnoticias/redacao/2019/11/28/com-novas-aprovacoes-liberacao-de-agrotoxicosja-e-o-maior-da-historia.htm. Acesso em: 11 abr. 2020.

REIS, M. C. "Reflecting on counter-hegemonic strategies of food and nutritional security: notes on the Brazilian case". In: BONANNO, Alessandro; WOLF, Steven A. (Org.) Resistance to the neoliberal agri-food regime: a critical analysis. Nova Iorque: Routledge, 2018, p. 95-105. 
RIVERO, S.; ALMEIDA, O.; ÁVILA, S.; OLIVEIRA, W. Pecuária e desmatamento: uma análise das principais causas diretas do desmatamento na Amazônia. Revista Nova Economia, Belo Horizonte, vol. 19, n. 1, 2009.

ROCHA, C. "Impactos à saúde humana causados pelos sistemas alimentares". In: PREISS, Potira V.; SCHNEIDER, Sergio; COELHO-DE-SOUZA, Gabriela (Org.) A contribuição brasileira à segurança alimentar e nutricional sustentável. Porto Alegre: Ed. UFRGS, 2020. 275 p.

SALLES-COSTA, R. O cenário atual da insegurança alimentar no Brasil. Rio de Janeiro: Instituto de Nutrição Josué de Castro/UFRJ, 2021.

SCHNEIDER, S.; SCHUBERT, M.; ESCHER, F. Regimes agroalimentares e o lugar da agricultura familiar: uma apresentação ao debate. Revista Mundi Meio Ambiente e Agrárias, Curitiba, vol. 1, n.1, 3, 2016.

SHIVA, V. Monoculturas da mente: perspectivas da biodiversidade e da biotecnologia. São Paulo: Gaia, 2003.

SILVA, Vicente de P. R. et al. Uma medida de sustentabilidade ambiental: pegada hídrica. Revista Brasileira de Engenharia Agrícola e Ambiental, Campina Grande, vol. 17, n. 1, p. 100-105, 2013. Disponível em: http://www.scielo.br/scielo.php?script=sci_arttext\&pid=S141543662013000100014\&lng=en\&nrm=iso. Accesso em: 13 nov. 2020. http://dx.doi.org/10.1590/S1415-43662013000100014.

TRICHES, R.; SCHNEIDER, S. Alimentação, sistema agroalimentar e os consumidores: novas conexões para o desenvolvimento rural. Cuadernos de Desarrollo Rural, 12 (75), p. 55-75. 2015. Disponível em: http://dx.doi. org/10.11144/Javeriana.cdr12-75.asac. Acesso em: 13 nov. 2020.

WILLETT, Walter et al. Food in the Anthropocene: the EAT-Lancet Commission on healthy diets from sustainable food systems. S.l.: The Lancet Comission, 2019. Disponível em: https://www.thelancet.com/pdfs/journals/lancet/PIIS0140-6736(18)317884.pdf?utm_campaign=tleat19\&utm_source=HubPage. Acesso em: 29 mar. 2019. 
Data de submissão: 24/04/2020

Data de aprovação: 09/06/2021

Revisão: Daniela Matthes (português), Anderson de Miranda Gomes (inglês) e Yanet María Reimondo Barrios (espanhol).

\author{
Karina de Paula Carvalho \\ Mestre em Desenvolvimento, Planejamento e Território \\ Praça Frei Orlando, 170 - Centro \\ 36307-352 São João del-Rei/MG, Brasil \\ Orcid: http://orcid.org/0000-0002-5674-1268 \\ E-mail: depaulacarvalhokarina@gmail.com \\ Rosa Livia Gonçalves Montenegro \\ Programa de Pós-Graduação em Desenvolvimento Planejamento e Território / \\ Universidade Federal de São João del-Rei \\ Praça Frei Orlando, 170 - Centro \\ 36307-352 São João del-Rei/MG, Brasil \\ Orcid: http://orcid.org/0000-0001-8383-5131 \\ E-mail: rosalivia@gmail.com
}

